\title{
Correction: Vialard, L., et al. Toward a Socio-Territorial Approach to Health: Health Equity in West Africa. Int. J. Environ. Res. Public Health 2017, 14, 106
}

\author{
Lucie Vialard ${ }^{1}$, Clara Squiban ${ }^{1}$, Gilles Riveau ${ }^{2}$, Emmanuel Hermann ${ }^{3}$, Doudou Diop ${ }^{2}$, \\ Florence Fournet ${ }^{4}$, Gérard Salem ${ }^{1,5}$ and Ellen E. Foley ${ }^{6, *}$ \\ 1 Laboratoire Dynamiques Sociales et Recomposition des Espaces (LADYSS), Université Paris Ouest Nanterre, \\ 92000 Nanterre, France; lucie.vialard@gmail.com (L.V.); clara.squiban@gmail.com (C.S.); \\ salem.gerard@gmail.com (G.S.) \\ 2 Biomedical Research Center EPLS, BP 226, Saint-Louis, Senegal; gilles.riveau@gmail.com (G.R.); \\ doudou.diop@espoir-sante.org (D.D.) \\ 3 Institut Pasteur of Lille, University of Lille, CNRS, Inserm, CHU Lille, Institut Pasteur de Lille, \\ U1019-UMR 8204-CIIL-Center for Infection and Immunity of Lille, F-59000 Lille, France; \\ emmanuel.hermann@univ-lille2.fr \\ 4 Unité Mixte de Recherche Maladies Infectieuses et Vecteurs: Ecologie, Génétique, Evolution \\ et Contrôle (MIVEGEC), Institut de Recherche pour le Développement, 34394 Montpellier, France; \\ florence.fournet@ird.fr \\ 5 Centre Population et Développement (CEPED), Université Paris Descartes-Institut de Recherche pour \\ le Développement, 75006 Paris, France \\ 6 International Development and Social Change, IDCE, Clark University, Worcester, MA 01610, USA \\ * Correspondence: efoley@clarku.edu
}

Academic Editor: Paul B. Tchounwou

Received: 10 May 2017; Accepted: 15 May 2017; Published: 8 June 2017

In the original version of our article [1], insufficient acknowledgement was given to the organizers of the medical survey. We apologize for this mistake. To correct this oversight, Gilles Riveau, Doudou Diop and Hermann Emmanuel have been added as authors.

The corrected list of authors and author contributions are provided below:

Lucie Vialard, Clara Squiban, Gilles Riveau, Emmanuel Hermann, Doudou Diop, Florence Fournet, Gérard Salem and Ellen E. Foley

The manuscript will be updated and the original will remain online on the article webpage, with a reference to this Correction.

Author Contributions: Gérard Salem, Ellen Foley and Florence Fournet conceived and designed the study experiments; Ellen Foley, Clara Squiban and Lucie Vialard performed the field research; Doudou Diop, Emmanuel Hermann, and Gilles Riveau organized and supervised the medical survey; Ellen Foley analysed the data with Lucie Vialard and Clara Squiban; Ellen Foley wrote the paper with the contribution of Lucie Vialard, Clara Squiban and Florence Fournet.

Conflicts of Interest: The authors declare no conflict of interest. The funding sponsors had no role in the design of the study; in the collection, analyses, or interpretation of data; in the writing of the manuscript, and in the decision to publish the results. 


\section{References}

1. Vialard, L.; Squiban, C.; Fournet, F.; Salem, G.; Foley, E.E. Toward a socio-territorial approach to health: Health equity in West Africa. Int. J. Environ. Res. Public Health 2017, 14, 106. [CrossRef] [PubMed] 